DOI: $10.24850 /$ j-tyca-2021-05-07

Artículos

\title{
Calidad de agua de uso agrícola en la cuenca media del río Jequetepeque, Perú
}

\section{Water quality for agriculture use in Jequetepeque middle river basin, Peru}

Ana M. Guerrero-Padilla1 ${ }^{1}$, ORCID: https://orcid.org/0000-0003-00083785

Carlos F. Cabrera-Carranza², ORCID: https://orcid.org/0000-00025821-5886

${ }^{1}$ Facultad de Ciencias Biológicas, Universidad Nacional de Trujillo, Trujillo, Perú, mguerrero@unitru.edu.pe

${ }^{2}$ Facultad de Ingeniería Geológica, Minera, Metalúrgica y Geográfica, Universidad Nacional Mayor de San Marcos, Lima, Perú, ccabrerac@unmsm.edu.pe

Autora para correspondencia: Ana M. Guerrero-Padilla, mguerrero@unitru.edu.pe

\section{Resumen}

La presente investigación tuvo como principal objetivo determinar la calidad del agua de uso agrícola en la cuenca media del río Jequetepeque, Perú. Se ubicaron seis estaciones de muestreo estación 
Ciencias ¿engua
2021, Instituto Mexicano de Tecnología del Agua Open Access bajo la licencia CC BY-NC-SA 4.0 (https://creativecommons.org/licenses/by-nc$\mathrm{sa} / 4.0 /)$

(Puente Kuntur Wasi, Sector La Mónica, Sector La Capilla, Cacerío Yatahual, Cacerío El Pongo y Puente Yonan) en la cuenca media del río Jequetepeque. Se determinaron parámetros físico-químicos, bacteriológicos e índice RAS. La calidad del agua en la zona de estudio se encontró dentro de los estándares de calidad de agua D.S. N0042017-MINAM, Categoría 3: Riego de vegetales y bebida de animales, y D1: Riego de vegetales, por lo que el agua puede ser usada sin restricciones para uso agrícola. Es importante indicar, en referencia a la evaluación bacteriológica, que los valores promedio de coliformes termotolerantes superaron los estándares de calidad de agua (1 000 $\mathrm{NMP} / 100 \mathrm{ml}$ ) debido a las aportaciones o vertimientos de origen doméstico. En el índice de RAS se encontraron valores menores a tres; en consecuencia, no es limitante el uso del agua para la actividad agrícola. Es de gran importancia realizar estudios de calidad de agua de todas las cuencas hidrográficas en el país, en especial para determinar la calidad del agua para riego por el potencial efecto sobre la salud humana y los ecosistemas.

Palabras clave: calidad de agua, cuenca Jequetepeque, índice RAS.

\section{Abstract}

This research had the main objective to determine water quality for agriculture use in Jequetepeque middle basin river, Peru. Six sampling station were located (Kuntur Wasi bridge, La Monica sector, La Capilla sector, Yatahual village, El Pongo village and Yonan bridge). The physical-chemical, bacteriological parameters and SAR index was determined. The water quality in the study area was found within the Water Quality Standards by Supreme Decree N004-2017-MINAM, according to Category 3: vegetable irrigation and animal drink, and 


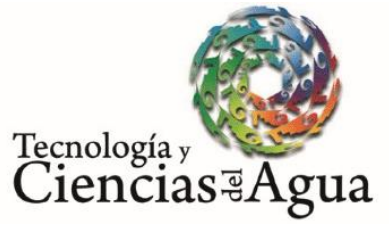

2021, Instituto Mexicano de Tecnología del Agua Open Access bajo la licencia CC BY-NC-SA 4.0 (https://creativecommons.org/licenses/by-nc$\mathrm{sa} / 4.0 /$ )

D1: vegetable irrigation, it used without restrictions for different crops. It is important in relation to bacteriological assessment, the average values of thermotolerant coliforms exceeded water quality (1 000 $\mathrm{NMP} / 100 \mathrm{ml}$ ) and indicating low organic pollution as consequence of the contributions or discharges of domestic origin. The SAR index found values lower than 3 , therefore it is not limiting for agricultural activity. It is great importance to carry out water quality studies of all river basin in the country, especially to assess water quality for irrigation due to potential effect on human health and ecosystem conservation.

Keywords: Water quality, Jequetepeque river, SAR index.

Recibido: $21 / 01 / 2020$

Aceptado: $24 / 09 / 2020$

\section{Introducción}

Los recursos hídricos juegan un rol vital en el desarrollo de la economía, agricultura, industria y progreso sostenible de los pueblos. La disponibilidad y calidad del agua superficial o subterránea se ha deteriorado por el incremento de la población, la industrialización y urbanización (Tyagi, Sharma, Singh, \& Dobhal, 2013); en tal sentido, la disponibilidad y calidad de las aguas son indicadores empleados para calcular el índice de sostenibilidad ambiental, que considera la 


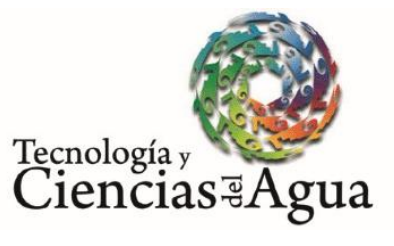

2021, Instituto Mexicano de Tecnología del Agua Open Access bajo la licencia CC BY-NC-SA 4.0 (https://creativecommons.org/licenses/by-nc$\mathrm{sa} / 4.0 /)$

habilidad de los países para proteger el medio ambiente en las próximas décadas (Balmaseda \& García, 2013). El recurso agua está sometido a la presión de una demanda cada vez más exigente en cantidad y calidad, condicionada por aspectos sociales, políticos y ambientales (Roldan, Díaz, Pérez, \& Moreno, 2010). Para lograr la gestión integrada del recurso hídrico se debe disponer de fuentes de información oportunas en cuanto a la calidad del agua (Bermejillo et al., 2012).

Las características fisicoquímicas y biológicas del agua varían por la contaminación antrópica. Los procesos y fenómenos naturales hacen que sus propiedades fisicoquímicas y biológicas varíen ampliamente de tramo en tramo a lo largo de la cuenca (Sutadian, Muttil, Yilmaz, \& Perera, 2016). Por la alta demanda de agua es relevante determinar su calidad para consumo humano, uso agrícola, industrial, acuícola, y conservación de la biodiversidad, y en actividades de recreación y aspectos estéticos (Rivera, Encina, Palma, \& Mejias, 2009). En consecuencia, es importante tener presente que la calidad de los recursos hídricos está muy relacionada con el bienestar social y el desarrollo económico de los pueblos; de ello depende el desarrollo y bienestar de las generaciones actuales y futuras (Ocampo-Duque, Osorio, Piamba, Schuhmacker, \& Domingo, 2013), así como el equilibrio de los ecosistemas de las diversas fuentes de agua, cuyos servicios ambientales permitirán la gestión integrada de los recursos hídricos, que incluye manejo, control y gestión del agua y sus usos, como actividades agropecuarias, silvicultura, ganadería, actividades industriales (Pawar, 2013; Gyawali, Techato, Yuangyai, \& Musikavong, 2013). 
Ciencias
2021, Instituto Mexicano de Tecnología del Agua Open Access bajo la licencia CC BY-NC-SA 4.0 (https://creativecommons.org/licenses/by-ncsa/4.0/)

Sutadian et al. (2016) y Medeiros et al. (2017 (citado en Pérez, Nardini, \& Galindo, 2018) afirman que la calidad de agua es uno de los temas más importantes en la gestión de recursos hídricos, y su clasificación se basa en el grado de pureza y contaminación; para ello se deben evaluar características físicas, químicas y biológicas (Rangeti, DzwairoBarratt, \& Otieno, 2015, citado en Pérez et al., 2018). Debido a la gran variedad de factores y parámetros que afectan la calidad de agua es compleja la evaluación final; en ese sentido, fue necesario usar indicadores de calidad de agua, los cuales son una herramienta muy útil para los programas de monitoreo, control y manejo del recurso hídrico. Diversos países utilizan los índices de calidad, lo cual varía enormemente de acuerdo con normatividades vigentes y/o programas o disposiciones que tienen que ver con las políticas de gobierno.

Estudios realizados en el río Amajac, México, presentaron valores superiores a la norma mexicana del índice de calidad de agua (ICA), como los resultados encontrados por Álvarez, Panta, Ayala y Acosta (2008) en sus valores para los sólidos solubles, sólidos totales, oxígeno disuelto, y coliformes totales y fecales. Asimismo, estudios realizados en el río Santa Cruz (RSC), Sonora, México, en la época de estiaje se reportaron concentraciones muy altas de los parámetros evaluados, excepto $\mathrm{pH}$ (referido a la norma mexicana). A diferencia de lo anterior, se consideró que la calidad del agua y la presencia de sedimentos en el río Santa Cruz, Sonora, fue buena en cuanto a concentraciones encontradas para los nitritos (Posada, Roldán, \& Ramírez, 2000). Sarabia-Meléndez, Cisneros-Almazán, Aceves-De-Alba, Durán-García y Castro-Larragoitia (2011) encontraron que los dos parámetros más importantes en la determinación de la calidad de agua de uso agrícola son la conductividad eléctrica (CE) y el índice de la relación de 
adsorción de sodio (RAS), estableciéndose la clasificación del agua de uso agrícola según las normas del Laboratorio de Salinidad de EUA.

Estudios realizados en Colombia en el año 2000 determinaron que los parámetros fisicoquímicos y biológicos evaluados en la cuenca Piedras Blancas, en Antioquia, presentaron bajas fluctuaciones a lo largo de la cuenca en estudio, con excepción del parámetro conductividad eléctrica y los sólidos totales, cuyas variaciones estuvieron relacionadas con la época de evaluación con la pluviosidad alta durante el periodo de ejecución del estudio (Solís, Israel, Nubes, Castillo, \& Meraz, 2011).

En Chile, Peña (1993) manifiesta que la calidad del agua para uso agrícola se ha visto restringida debido a la cantidad de boro que presenta, sobre todo en la región Altiplánica (Norte Grande), donde con frecuencia las aguas superan niveles de boro tan altos como 5.0 $\mathrm{mg} / \mathrm{l}$, incidiendo principalmente a cultivos sensibles a este elemento (cítricos), los cuales son afectados por concentraciones de $0.3 \mathrm{mg} / \mathrm{l}$. Asimismo, la zona del Norte Chico es afectada por contenido de boro en las aguas con valores cercanos a $1.5 \mathrm{mg} / \mathrm{l}$, que siguen siendo elevados para producir limitaciones en el uso del recurso.

Reinaudi, Grégoire, Rosiére, Nadal y Viñuela (1998) estudiaron la calidad del agua para riego en invernáculos de la Región Central de La Pampa, Argentina, y encontraron que la concentración de arsénico total era superior a lo permitido por la Organización Mundial de la Salud (OMS). Asimismo, Báez (1999), en Buenos Aires, indicó la existencia de problemas más importantes asociados con la calidad de agua de riego: la salinización y sodificación del suelo, al generar deterioro de las propiedades del suelo, aunque algunos cultivos como Triticum 
Tecnología y

Ciencias $\approx$ Agua
2021, Instituto Mexicano de Tecnología del Agua Open Access bajo la licencia CC BY-NC-SA 4.0 (https://creativecommons.org/licenses/by-nc$\mathrm{sa} / 4.0 /)$

aestivum "trigo" produjo rendimientos aceptables incluso con niveles de salinidad relativamente elevados.

En el Perú, la Estrategia Nacional para la Gestión de los Recursos Hídricos Continentales establece la protección de la calidad de los recursos hídricos; es relevante la implementación de mecanismos necesarios para la protección de las cuencas hidrográficas y acuíferos. Se ha determinado de manera fehaciente que la calidad del agua es afectada en particular por el vertimiento de efluentes de relaves mineros, que contienen metales pesados, los cuales son evacuados directamente, sin tratamiento alguno, en las cuencas hidrográficas; así, algunas de esas cuencas tienen grandes problemas por lo difícil que resulta revertir el efecto e impacto negativo en los cuerpos de agua; las cuencas de los ríos Mantaro, Rímac, Santa e Ilo, entre otras, presentan gran contaminación química, que causa pérdida de la biodiversidad y deterioro de ecosistemas (INRENA, 2003). En la Región La Libertad, las cuencas con mayor deterioro o contaminación son las de los ríos Moche y Jequetepeque, con bioacumulación de contaminantes minero-metalúrgicos y sedimentos, y por el uso indiscriminado de agroquímicos, causantes de pérdida de cadenas tróficas, biodiversidad y disminución de la capacidad productiva de los suelos agrícolas de los valles Moche y Jequetepeque (Juarez, 2006).

Existen proyectos agrícolas de gran envergadura para el desarrollo del país, pero desafortunadamente carecen de un adecuado manejo de los proyectos de riego, lo cual trae consecuencias negativas a las comunidades, cuyo objetivo primordial era alcanzar el desarrollo sostenible desde el enfoque económico, social y ambiental. La complejidad de las interacciones de los procesos ambientales y el desarrollo de los sistemas de riego y drenaje presentan alta dificultad 
de predicción de tipos de impacto y/o cambios en la naturaleza. Sin embargo, en la actualidad, con los estudios en detalle, estratégicos, económicos, ambientales, se podrían manejar y controlar las diferentes interacciones de las actividades humanas, áreas agrícolas y los recursos hídricos a ser usados en las diferentes actividades, evitando los posibles impactos negativos que podrían producirse en la zona de desarrollo.

Es necesario conocer el estado situacional de la cuenca del río Jequetepeque, con énfasis en la parte media, evaluando la oferta y demanda hídrica, calidad de agua en el escenario de eventos hidrológicos, cuyos resultados permitirá contar con información básica en la toma de decisiones de las autoridades a distintos niveles y proponer una gestión integrada de la cuenca del río Jequetepeque. Asimismo, determinar los impactos generados por las actividades desarrolladas que afecten la calidad del agua de uso agrícola; ello, con un enfoque a largo plazo, que garantice una visión completa e integrada del significado de las actividades agrícolas asociada con la calidad del agua, a fin de contribuir en el manejo de la calidad del agua de uso agrícola de la cuenca media del río Jequetepeque, Perú.

\section{Materiales y métodos}

\section{Área de estudio}




\section{Tecnología y
Ciencias $₫$ Agua}

2021, Instituto Mexicano de Tecnología del Agua Open Access bajo la licencia CC BY-NC-SA 4.0 (https://creativecommons.org/licenses/by-nc$\mathrm{sa} / 4.0 /)$

El río Jequetepeque nace en la pequeña laguna ubicada al pie del cerro Agopití, en la provincia y departamento de Cajamarca, a los $07^{\circ} 20^{\prime}$ latitud sur, y $78^{\circ} 21^{\prime}$ latitud oeste, a 4000 msnm; la cuenca recorre unos $150 \mathrm{~km}$ de este a oeste, desde los $4000 \mathrm{msnm}$; colecta en su trayecto el drenaje de más de 30 ríos secundarios, riachuelos y quebradas menores, y se embalsa en la represa Gallito Ciego. Los principales tributarios del río Jequetepeque se extienden entre los 600 y 2500 msnm. Los constituyentes más determinantes del paisaje vegetal se encuentran aislados uno de otros, dejando espacio para multitud de pequeñas hierbas que brotan durante la corta estación de lluvias, donde también aparecen las hojas de los arbustos.

El río Jequetepeque es el resultado de la confluencia de los ríos Puclush y Magdalena, los mismos que se unen a la altura del pueblo de Llallán, en una cota aproximada de $710 \mathrm{msnm}$ aguas abajo; recibe los aportes del río Pallac por la margen derecha y de la quebrada Chausis por la margen izquierda. El sistema hidrográfico de la subcuenca Puclush es la que aporta mayor cantidad de agua al río Jequetepeque debido a las precipitaciones de la parte alta, la presencia de lagunas y vegetación arbórea arbustiva y de pastos. El río Magdalena nace en las alturas de Huacrarucro; inicialmente recibe los aportes del río Chotén y el río Naranjo por la margen derecha, y del río Asunción por la margen izquierda; toma el nombre de río Magdalena a la altura de Choropampa, con una cota aproximada de $1600 \mathrm{msnm}$; sus principales afluentes por la margen derecha son los ríos La Viña, Chetillano y Llaminchan o San Pablo; por la margen izquierda tiene los siguientes afluentes: río Chonta, río Huertas y río Contumazá. 


\section{Toma de muestras}

La toma de muestras en las estaciones de muestreo correspondió en los periodos de cambios estacionales, de avenida y estiaje; la frecuencia de muestreo fue dos veces al mes, en cada una de las estaciones de muestreo, de acuerdo con lo establecido en la Resolución Jefatural N010-2016-Autoridad Nacional del Agua: Protocolo Nacional para el Monitoreo de la Calidad de los Recursos Hídricos Superficiales (ANA, 2016). El estudio comprendió el periodo de muestreo (diciembre de 2018 a mayo de 2019), siguiendo las normas internacionales (GEMS, 1987). Se seleccionaron seis estaciones de muestreo (Tabla 1 y Figura 1) con base en las normas establecidas por Global Environmental Monitoring System (GEMS, 1987). Los equipos portátiles que se usaron en la presente investigación fueron los siguientes: equipo multiparámetro HI 991300 (marca HANNA), medidor de $\mathrm{pH}$, conductividad eléctrica (CE), sólidos totales disueltos (TDS) y temperatura; equipo multiparámetro HI 9829 (marca HANNA), medidor de $\mathrm{pH}, \mathrm{mV}, \mathrm{ORP}, \mathrm{OD}, \mathrm{CE}$, TDS, resistividad, salinidad, temperatura, presión atmosférica y turbidez.

Tabla 1. Georreferenciación y altitud en la ubicación de las estaciones de muestreo en la cuenca media del río Jequetepeque, Perú. 
2021, Instituto Mexicano de Tecnología del Agua Open Access bajo la licencia CC BY-NC-SA 4.0 (https://creativecommons.org/licenses/by-ncsa/4.0/)

\begin{tabular}{|l|c|c|c|}
\hline \multicolumn{1}{|c|}{$\begin{array}{c}\text { Estaciones de } \\
\text { muestreo }\end{array}$} & \multicolumn{2}{|c|}{$\begin{array}{c}\text { Coordenadas } \\
\text { UTM } \\
\text { (msnm) }\end{array}$} \\
\cline { 2 - 4 } $\begin{array}{l}\text { E-1 (Puente Kurtur } \\
\text { Wasi) }\end{array}$ & $7^{\circ} 13^{\prime} 23^{\prime \prime} \mathrm{S}$ & $78^{\circ} 50^{\prime} 51^{\prime \prime} \mathrm{W}$ & 837 \\
\hline $\begin{array}{l}\text { E-2 (Sector La } \\
\text { Mónica) }\end{array}$ & $7^{\circ} 13^{\prime} 39^{\prime \prime} \mathrm{S}$ & $78^{\circ} 54^{\prime} 04^{\prime \prime} \mathrm{W}$ & 759 \\
\hline $\begin{array}{l}\text { E-3 (Sector La } \\
\text { Capilla) }\end{array}$ & $7^{\circ} 12^{\prime} 16^{\prime \prime} \mathrm{S}$ & $78^{\circ} 56^{\prime} 21^{\prime \prime} \mathrm{W}$ & 689 \\
\hline $\begin{array}{l}\text { E-4 (Cacerío } \\
\text { Yatahual) }\end{array}$ & $7^{\circ} 10^{\prime} 03^{\prime \prime} \mathrm{S}$ & $79^{\circ} 01^{\prime} 17^{\prime \prime} \mathrm{W}$ & 596 \\
\hline $\begin{array}{l}\text { E-5 (Cacerío El } \\
\text { Pongo) }\end{array}$ & $7^{\circ} 12^{\prime} 22^{\prime \prime} \mathrm{S}$ & $79^{\circ} 02^{\prime} 52^{\prime \prime} \mathrm{W}$ & 552 \\
\hline $\begin{array}{l}\text { E-6 (Puente Yonan) } \\
7^{\circ} 15^{\prime} 17^{\prime \prime} \mathrm{S}\end{array}$ & $79^{\circ} 06^{\prime} 03^{\prime \prime} \mathrm{W}$ & 448 \\
\hline
\end{tabular}


2021, Instituto Mexicano de Tecnología del Agua

Tecnología y Open Access bajo la licencia CC BY-NC-SA 4.0 (https://creativecommons.org/licenses/by-nc$\mathrm{sa} / 4.0 /$ )

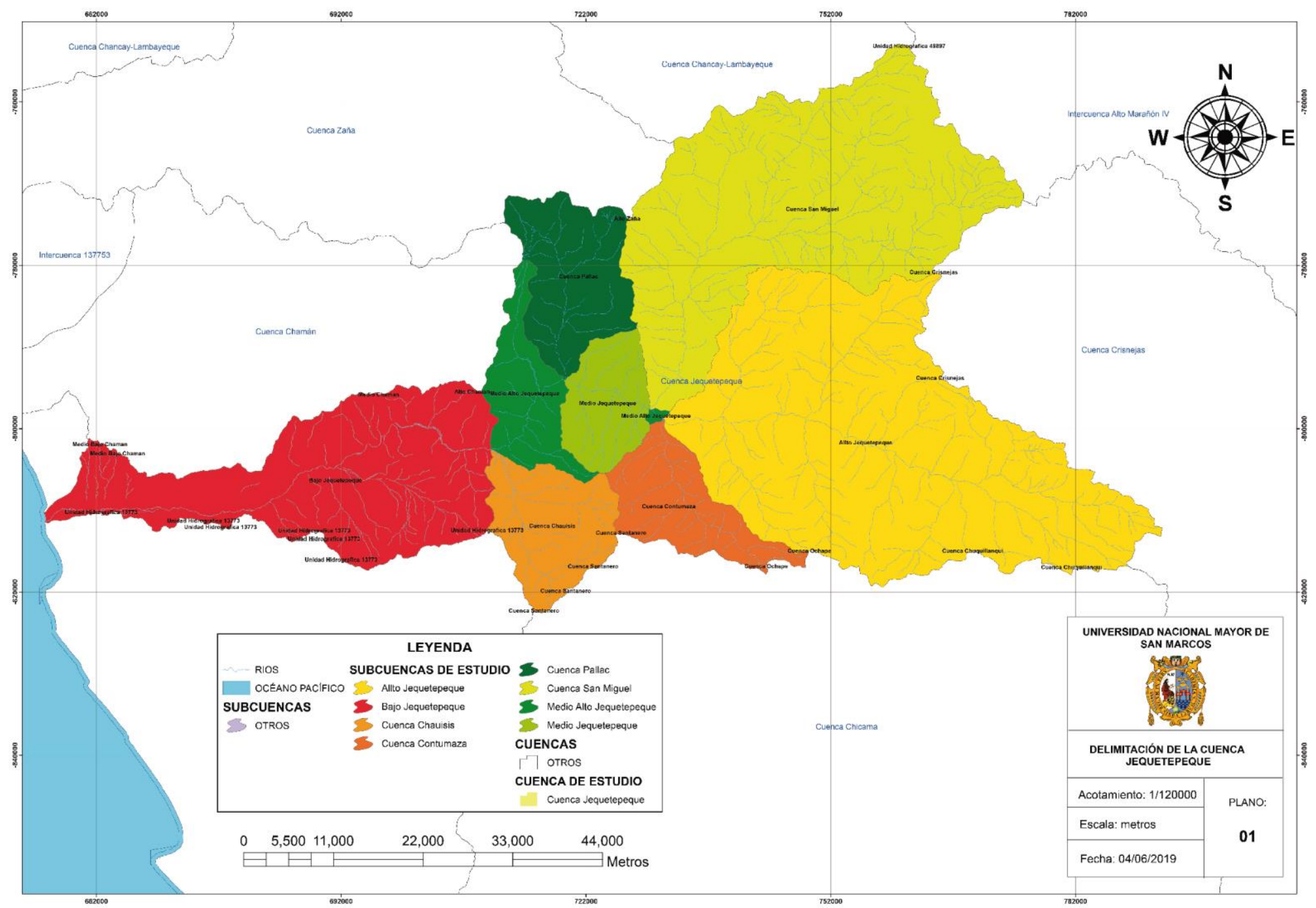

Figura 1. Delimitación de la cuenca media del río Jequetepeque, Perú.

La presente investigación fue de tipo longitudinal, con diseño de tendencia (Hernández, Fernández, \& Baptista, 2010). La información correspondiente a la disponibilidad hídrica (oferta y demanda) de la cuenca del río Jequetepeque se registró en una base de datos en la aplicación de Test para normalidad multivariada, distribución normal bivalente; se empleó un coeficiente de correlación no paramétrico 
Ciencias ¿engua
2021, Instituto Mexicano de Tecnología del Agua Open Access bajo la licencia CC BY-NC-SA 4.0 (https://creativecommons.org/licenses/by-nc$\mathrm{sa} / 4.0 /$ )

como el de Spearman y la prueba de distribución bivalente de Wilcoxon (Hines \& Montgomery, 1996) debido a que sí existe relación entre los volúmenes de agua por la cual discurre en la cuenca hidrológica y la calidad de agua, tan es así que en época de avenida se pueden encontrar mayores concentraciones de sólidos totales disueltos, y la posibilidad de mayor dilución o concentración de contaminantes como metales pesados.

El análisis estadístico Wilcoxon es una prueba no paramétrica que se usa al comparar el rango medio de dos muestras relacionadas y así determinar si existen diferencias entre ellas. Se utiliza como alternativa a la prueba $t$ de Student cuando no se puede suponer la normalidad de dichas muestras. Es una prueba no paramétrica de comparación de dos muestras relacionadas y por lo tanto no necesita una distribución específica. En el caso de los volúmenes de las cuencas, como es el caso de la cuenca Jequetepeque, es muy irregular, por tanto se usa más bien el nivel ordinal de la variable dependiente. Se utiliza para comparar dos mediciones relacionadas y determinar si la diferencia entre ellas se debe al azar o no (en este último caso, que la diferencia sea estadísticamente significativa).

El empleo del coeficiente de correlación de Spearman (rho) se usa para evaluar la asociación entre dos variables que tienen categorías ordinales. Las categorías ordinales tienen un orden natural. El coeficiente puede variar de -1 a +1 . La interpretación rho de Spearman concuerda en valores próximos a 1 ; indican una correlación fuerte y positiva. Valores próximos a -1 indican una correlación fuerte y negativa. Valores próximos a cero indican que no hay correlación lineal; puede que exista otro tipo de correlación, pero no lineal. 
Se evaluaron parámetros físico-químicos de acuerdo con las normas APHA-AWWA-WEF (2012) y bacteriológicos (NMP/100 ml), cuyos métodos para cada uno de los parámetros evaluados se detalla en la Tabla 2; para uso agrícola, Categoría 3: Riego de vegetales y bebida de animales, y D1: Riego de vegetales, con base en estándares de calidad de agua D.S. N004-2017-MINAM; asimismo, se determinó el índice RAS (Ayers \& Westcot, 1987; Rashidi \& Seilsepour, 2011).

Tabla 2. Parámetros físico-químicos y bacteriológicos según métodos para su determinación en la evaluación de calidad de agua

\begin{tabular}{|l|l|l|}
\hline $\begin{array}{c}\text { Parámetros físico- } \\
\text { químicos y } \\
\text { bacteriológicos }\end{array}$ & Año \\
\hline Temperatura & $\begin{array}{l}\text { Standard Methods for the analysis of } \\
\text { water and wastewater, 22 ND edition. } \\
\text { SM 2550 B }\end{array}$ & 2012 \\
\hline $\begin{array}{l}\text { Potencial de } \\
\text { hidrógeno (pH) }\end{array}$ & $\begin{array}{l}\text { Standard Methods for the analysis of } \\
\text { water and wastewater, 22 ND edition. } \\
\text { SM 4500-H+ -B }\end{array}$ & 2012 \\
\hline Conductividad (CE) & $\begin{array}{l}\text { Standard Methods for the analysis of } \\
\text { water and wastewater, 22 ND edition. } \\
\text { SM 2510 B }\end{array}$ & 2012 \\
\hline $\begin{array}{l}\text { Sólidos totales } \\
\text { disueltos (STD) }\end{array}$ & $\begin{array}{l}\text { Standard Methods for the analysis of } \\
\text { water and wastewater, 22 ND edition. } \\
\text { SM 2540 C }\end{array}$ & 2012 \\
\hline
\end{tabular}


Ciencias Ciengua
2021, Instituto Mexicano de Tecnología del Agua Open Access bajo la licencia CC BY-NC-SA 4.0 (https://creativecommons.org/licenses/by-nc$\mathrm{sa} / 4.0 /)$

\begin{tabular}{|c|c|c|}
\hline Carbonatos $\left(\mathrm{CO}_{3}\right)$ & $\begin{array}{l}\text { Standard Methods for the analysis of } \\
\text { water and wastewater, } 22 \text { ND edition. } \\
\text { SM } 2320 \text { B }\end{array}$ & 2012 \\
\hline Bicarbonatos $\left(\mathrm{HCO}_{3}\right)$ & $\begin{array}{l}\text { Standard Methods for the analysis of } \\
\text { water and wastewater, } 22 \text { ND edition. } \\
\text { SM } 2320 \text { B }\end{array}$ & 2012 \\
\hline Cloruros $\left(\mathrm{Cl}^{-1}\right)$ & $\begin{array}{l}\text { Standard Methods for the analysis of } \\
\text { water and wastewater, } 22 \text { ND edition. } \\
\text { SM } 4500-\mathrm{Cl}-\text {-B }\end{array}$ & 2012 \\
\hline $\begin{array}{l}\text { Oxígeno disuelto } \\
\left(\mathrm{O}_{2}\right)\end{array}$ & $\begin{array}{l}\text { Standard Methods for the analysis of } \\
\text { water and wastewater, } 22 \text { ND edition. } \\
\text { SM } 5210 \text { B }\end{array}$ & 2012 \\
\hline $\begin{array}{l}\text { Demanda bioquímica } \\
\text { de oxígeno }\left(\mathrm{DBO}_{5}\right)\end{array}$ & $\begin{array}{l}\text { Standard Methods for the analysis of } \\
\text { water and wastewater, } 22 \text { ND edition. } \\
\text { SM } 5210 \text { B }\end{array}$ & 2012 \\
\hline $\begin{array}{l}\text { Coliformes totales } \\
(\mathrm{NMP} / 100 \mathrm{ml})\end{array}$ & $\begin{array}{l}\text { Standard Methods for examination of } \\
\text { water and wastewater APHA, AWWA, } \\
\text { WEF }\end{array}$ & 2012 \\
\hline $\begin{array}{l}\text { Coliformes } \\
\text { termotolerantes } \\
(\mathrm{NMP} / 100 \mathrm{ml})\end{array}$ & $\begin{array}{l}\text { Standard Methods for examination of } \\
\text { water and wastewater APHA, AWWA, } \\
\text { WEF }\end{array}$ & 2012 \\
\hline $\begin{array}{l}\text { Parámetros } \\
\text { químicos }\end{array}$ & Métodos & Año \\
\hline Calcio $\left(\mathrm{Ca}^{+2}\right)$ & $\begin{array}{c}\text { Calcium. EDTA Tritrimetric } \\
\text { Method.3500-Ca B. APHA-AWWA- } \\
\text { WEF. 23rd Edition. }\end{array}$ & 2017 \\
\hline
\end{tabular}


2021, Instituto Mexicano de Tecnología del Agua Open Access bajo la licencia CC BY-NC-SA 4.0 $\mathrm{sa} / 4.0 /$ )

\begin{tabular}{|c|c|c|}
\hline Magnesio $\left(\mathrm{Mg}^{+2}\right)$ & $\begin{array}{l}\text { Magnesium. Calculation Method. } \\
\text { 3500-Mg B. APHA-AWWA-WEF. 23rd } \\
\text { Edition. }\end{array}$ & 2017 \\
\hline Sodio $\left(\mathrm{Na}^{+1}\right)$ & $\begin{array}{c}\text { Metals by Flame Atomic Absorption } \\
\text { Spectrometry. Direct Air-Acetylene } \\
\text { Flame Method. } 3111 \text { B. APHA-AWWA- } \\
\text { WEF. 23rd Edition. }\end{array}$ & 2017 \\
\hline Plomo (Pb) & $\begin{array}{l}\text { SMEWW-APHA-AWWA-WEF Part } 3111 \\
\text { B, 23rd Ed. } 2017 \text { Metals by Flame } \\
\text { Atomic Absorption Spectrometry. } \\
\text { Direct Air-Acetylene Flame Method }\end{array}$ & 2017 \\
\hline Cadmio (Cd) & $\begin{array}{l}\text { SMEWW-APHA-AWWA-WEF Part } 3111 \\
\text { B, 23rd Ed. } 2017 \text { Metals by Flame } \\
\text { Atomic Absorption Spectrometry. } \\
\text { Direct Nitrous Oxide-Acetylene Flame } \\
\text { Method }\end{array}$ & 2017 \\
\hline
\end{tabular}

El agua de uso agrícola se evalúa por el riesgo potencial debido a que las aguas pueden ser consideradas potencialmente peligrosas si presentan concentraciones de sales, lo cual es perjudicial, y es evidente cuando las aguas riegan los suelos agrícolas, haciendo que estos suelos se salinicen y en consecuencia pierdan su productividad (FAO, 2002). Cuando se produce la evaporación, el porcentaje de retención de agua en el suelo disminuye y en consecuencia es menor la humedad del suelo, no se produce la eliminación de las sales, de manera que el suelo se saliniza y se produce pérdida de agua. Si el agua de riego tiene una concentración de sales (inicial), y ésta se encuentra en los límites 


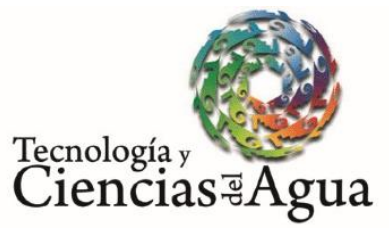

2021, Instituto Mexicano de Tecnología del Agua Open Access bajo la licencia CC BY-NC-SA 4.0 (https://creativecommons.org/licenses/by-ncsa/4.0/)

permisibles, puede haber mayor salinidad en el suelo por la evaporación del agua. Por otro lado, la concentración de las sales puede alcanzar el valor límite de solubilidad y, en consecuencia, las sales se precipitan; esto se determina por la presencia de cationes de calcio, magnesio y sodio, aniones (cloruros), que no se encuentran en equilibrio, y tienen una relación directa con el $\mathrm{pH}$, alterando las concentraciones iniciales. Cuando sales de calcio están presentes se produce una baja solubilidad, en consecuencia, se incrementan las concentraciones de sodio, alterando el porcentaje del catión sodio intercambiable en el suelo (Romero, 2013).

Para evaluar el índice de relación de absorción de sodio (RAS), índice de relación de absorción de sodio ajustado (RAS ajustado), se requiere determinar el carbonato sódico residual, dureza del agua, cationes de calcio $\left(\mathrm{Ca}^{+2}\right)$ y magnesio $\left(\mathrm{Mg}^{+2}\right)$, los cuales son relacionados con la calidad de agua para uso agrícola, determinando finalmente el tipo de cultivos a desarrollar (Ayers \& Westcot, 1987; Rashidi \& Seilsepour, 2011). Para los parámetros a evaluar se tuvieron en cuenta los estándares de calidad ambiental para agua categoría IIIRiego de vegetales y bebida de animales descritos en el Decreto Supremo N004-2017-MINAM (MINAM, 2017).

\section{Resultados y discusión}


El balance hídrico de la cuenca del Jequetepeque se hizo con información de 2017-2018. Debido a que ocurrió el evento El Niño en la zona en estudio y la principal demanda es de uso agrícola, se emplea el aporte de lluvias estacionales y se complementa con el riego en época de estiaje. Como se puede observar, se presentó mayor oferta y demanda durante los meses de febrero, marzo y abril (Figura 2), lo cual va disminuyendo de mayo a julio. Se tiene mayor oferta al $75 \%$ de persistencia de $749.96 \mathrm{hm}^{3}$ y oferta real de $142.35 \mathrm{hm}^{3}$ en marzo de 2018. En la Figura 3 se puede observar que la oferta ejecutada, $749.96 \mathrm{hm}^{3}$, superó a la oferta programada de $142.35 \mathrm{hm}^{3}$, haciendo una diferencial de $607.61 \mathrm{hm}^{3}$ para el año hídrico 2017-2018. La mayor demanda bruta programada fue $129.8029319 \mathrm{hm}^{3}$ y la ejecutada $111.1599072 \mathrm{hm}^{3}$ (Figura 4) para todos los usos fue en febrero, mientras que el mayor diferencial ocurrió en diciembre (32.66550747 $\mathrm{hm}^{3}$ ) y marzo (34.49521828 $\mathrm{hm}^{3}$ ) (Figura 5). 
Teçnología y

Ciencias $₫$ Agua
2021, Instituto Mexicano de Tecnología del Agua Open Access bajo la licencia CC BY-NC-SA 4.0 (https://creativecommons.org/licenses/by-nc$\mathrm{sa} / 4.0 /)$

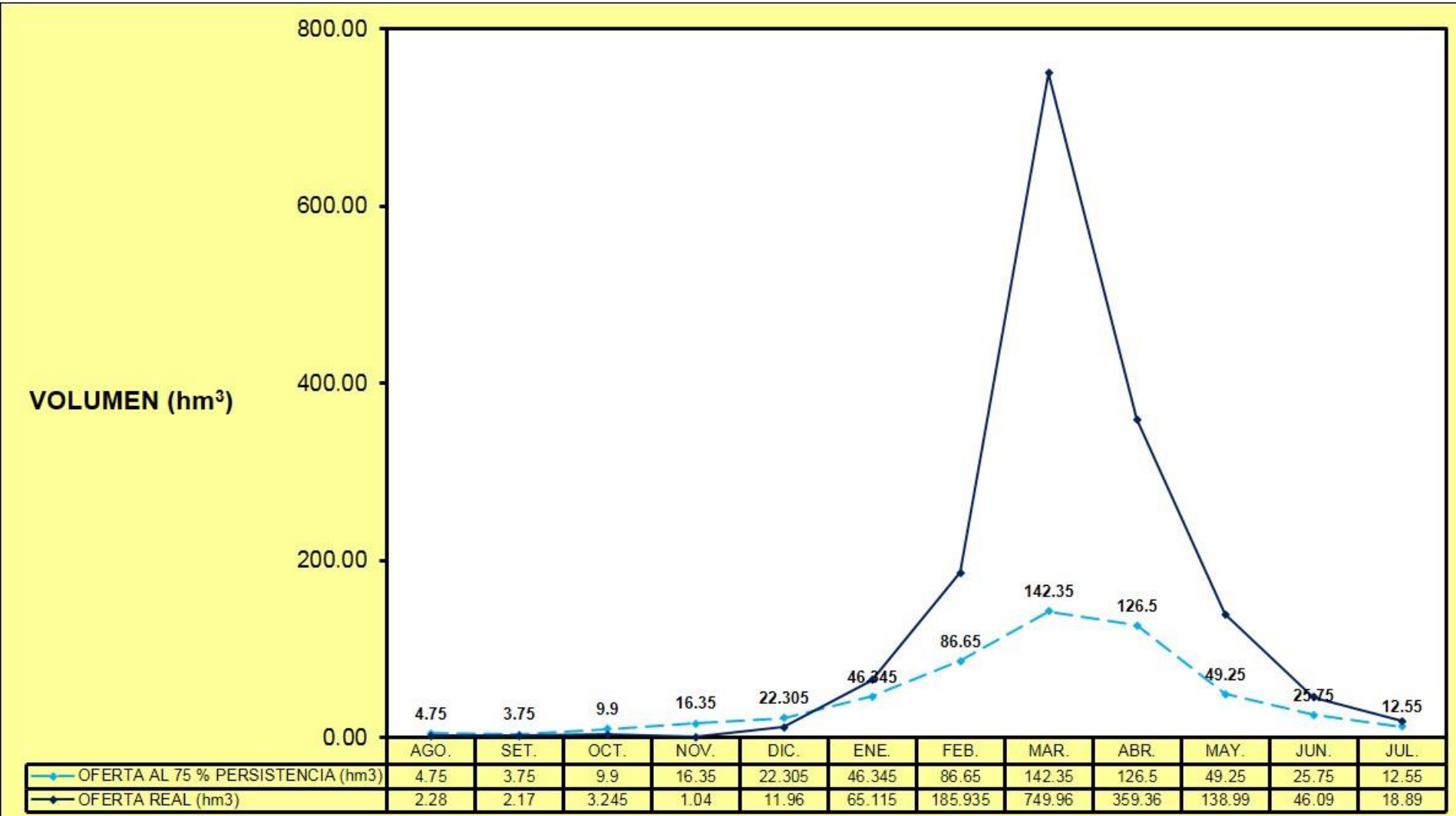

Figura 2. Oferta hídrica real al $75 \%$ de persistencia en la cuenca del río Jequetepeque, Perú (agosto 2017-julio 2018). 


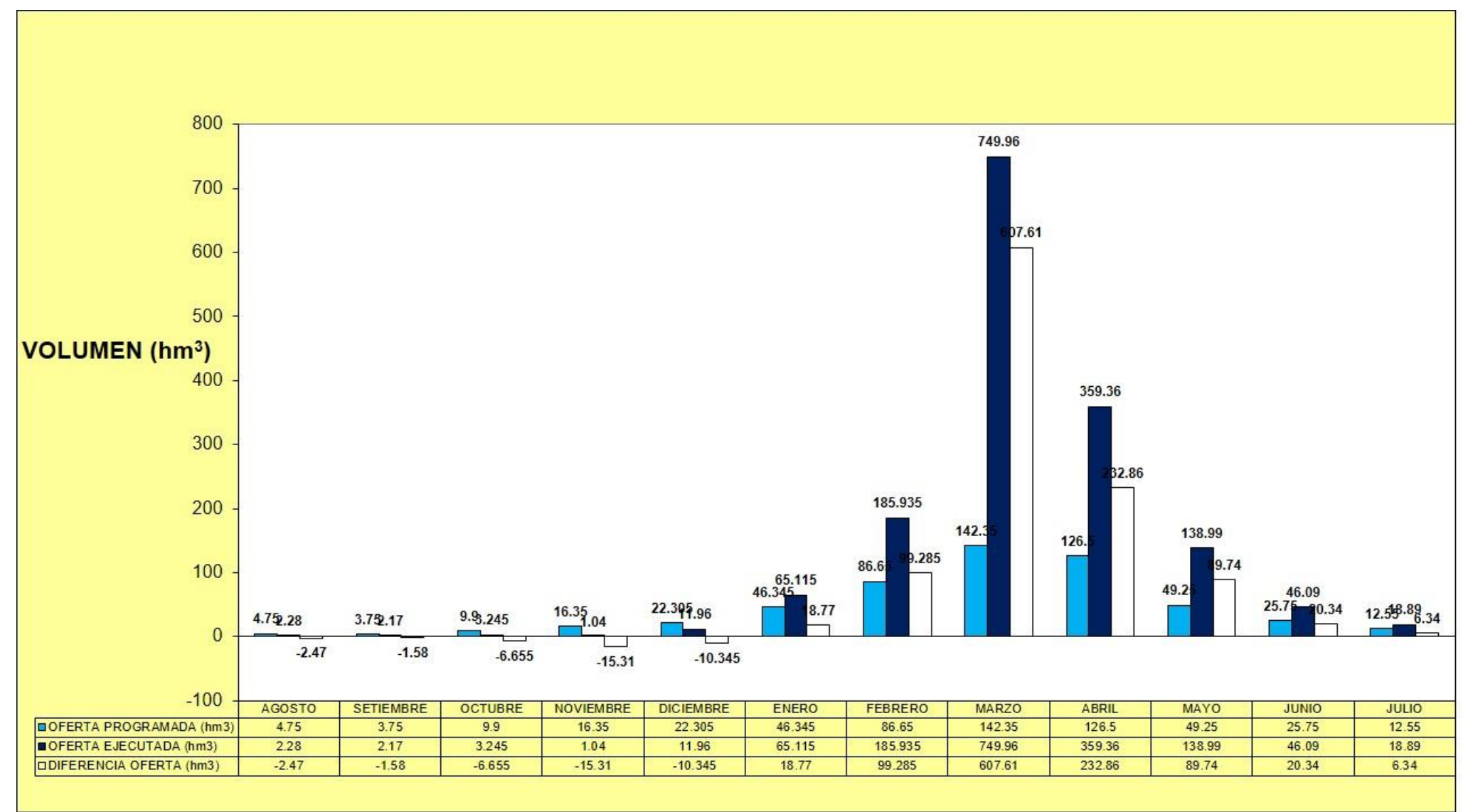

Figura 3. Oferta hídrica programada y ejecutada, y su diferencial en la cuenca del río Jequetepeque, Perú (agosto 2017-julio 2018). 
2021, Instituto Mexicano de Tecnología del Agua Open Access bajo la licencia CC BY-NC-SA 4.0 (https://creativecommons.org/licenses/by-nc$\mathrm{sa} / 4.0 /)$

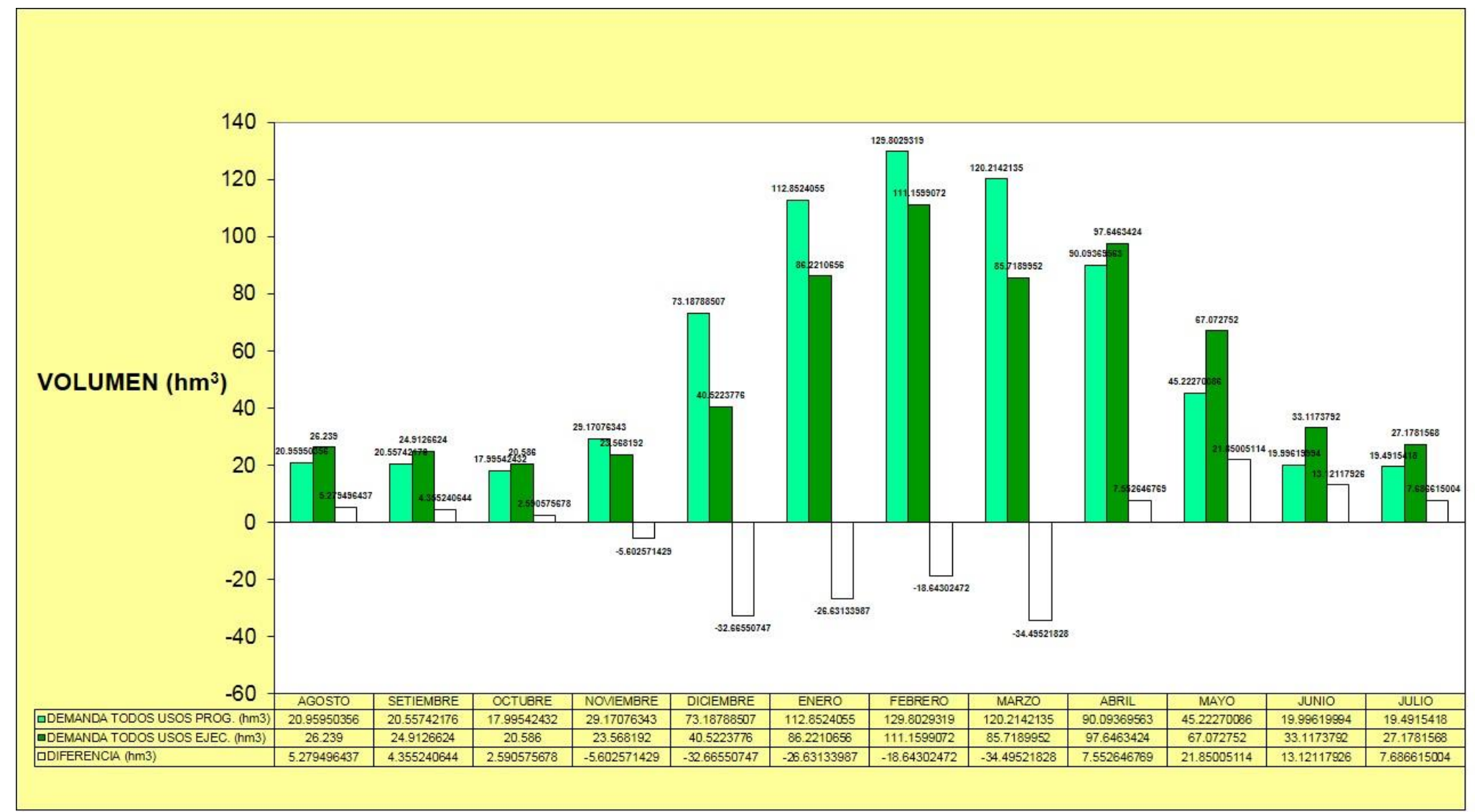

Figura 5. Demanda bruta programada y ejecutada, y su diferencial en la cuenca del río Jequetepeque, Perú (agosto 2017-julio 2018).

La más alta demanda agrícola (Figura 6) fue en el mes de febrero, programada (125.8572167 $\left.\mathrm{hm}^{3}\right)$ y ejecutada (106.8053472 $\left.\mathrm{hm}^{3}\right)$; mientras que el mayor diferencial se produjo en los meses de marzo $\left(35.08446628 \mathrm{hm}^{3}\right.$ ) y diciembre (33.12083547 hm³) (Figura 7). 
Para la determinación de la normalidad bivalente se requiere evaluar la relación entre la oferta y la demanda hídrica si ambas variables seguían una distribución normal. Si eran distribución normal bivalente (Tabla 3, Tabla 6, Tabla 9), era necesario el empleo de la correlación de Pearson, la cual indicó que no existía distribución normal bivalente, y en tal caso fue necesario el empleo de un coeficiente de correlación no paramétrico como el de Spearman. Cuando se evaluó mediante esta correlación de Spearman (Tabla 4, Tabla 7, Tabla 10), se encontraron dos variables que se relacionan muy fuertemente porque su valor fue $P<0.05$. Asimismo, con la prueba de distribución bivalente de Wilcoxon (Tabla 5, Tabla 8, Tabla 11) se encontró significancia asintótica de 0.638 y 0.53 para la oferta y demanda hídrica, respectivamente (Tabla 6 y Tabla 7), en la cuenca del río Jequetepeque 2017-2018.

Tabla 3. Test para normalidad multivariada en relación con la oferta hídrica de la cuenca Jequetepeque durante 2017-2018.

\begin{tabular}{|l|l|l|}
\hline $\begin{array}{l}\text { Henze-Zirkler }= \\
1.520446\end{array}$ & Chi2(1) = 13.256 & $\begin{array}{l}\text { Prob }>\text { chi2 }= \\
0.0003\end{array}$ \\
\hline Doornik-Hansen & Chi2(4) = 37.525 & $\begin{array}{l}\text { Prob }>\text { chi2 }= \\
0.0000\end{array}$ \\
\hline
\end{tabular}

Tabla 4. Programa de Spearman, stats (rho p) pw en relación con la oferta hídrica de la cuenca Jequetepeque durante 2017-2018.

\begin{tabular}{|l|c|}
\hline \multicolumn{2}{|c|}{ Programa Spearman ejecutado, stats (rho p) pw } \\
\hline Número de objetos & 12 \\
\hline
\end{tabular}


2021, Instituto Mexicano de Tecnología del Agua Open Access bajo la licencia CC BY-NC-SA 4.0

Tecnología y (https://creativecommons.org/licenses/by-nc$\mathrm{sa} / 4.0 /)$

\begin{tabular}{|l|c|}
\hline rho de Spearman & 0.9161 \\
\hline \multicolumn{2}{|l|}{ Test de Ho: programa para ejecutar si son variables independientes } \\
\hline Prob $>|\mathrm{t}|$ & 0.0000 \\
\hline
\end{tabular}

Tabla 5. Prueba de rangos con signo de Wilcoxon para muestras relacionadas según oferta hídrica de la cuenca Jequetepeque durante 2017-2018.

\begin{tabular}{|l|c|}
\hline \multicolumn{1}{|c|}{ Datos } & Resultados \\
\hline Número total & 12 \\
\hline Estadístico de contraste & 60.000 \\
\hline Error estándar & 12.748 \\
\hline Estadístico de contraste estandarizado & 1.647 \\
\hline Sig. asintótica (prueba bilateral) & 0.099 \\
\hline
\end{tabular}

Tabla 6. Test para normalidad multivariada en relación con la demanda bruta de la cuenca Jequetepeque durante 2017-2018.

\begin{tabular}{|l|l|l|}
\hline $\begin{array}{l}\text { Henze-Zirkler }= \\
0.8018365\end{array}$ & Chi2(1) =4.479 & $\begin{array}{l}\text { Prob }>\text { chi2 }= \\
0.0343\end{array}$ \\
\hline Doornik-Hansen & Chi2(4) $=8.533$ & $\begin{array}{l}\text { Prob }>\text { chi2 }= \\
0.0739\end{array}$ \\
\hline
\end{tabular}

Tabla 7. Programa de Spearman, stats (rho p) pw en relación con la demanda bruta de la cuenca Jequetepeque durante 2017-2018.

\section{Programa Spearman ejecutado, stats (rho p) pw}


2021, Instituto Mexicano de Tecnología del Agua Open Access bajo la licencia CC BY-NC-SA 4.0

Teçnología y (https://creativecommons.org/licenses/by-nc$\mathrm{sa} / 4.0 /)$

\begin{tabular}{|l|c|}
\hline Número de objetos & 12 \\
\hline rho de Spearman & 0.8392 \\
\hline \multicolumn{2}{|c|}{ Test de Ho: programa para ejecutar si son variables independientes } \\
\hline Prob $>|\mathrm{t}|$ & 0.0006 \\
\hline
\end{tabular}

Tabla 8. Prueba de rangos con signo de Wilcoxon para muestras relacionadas según demanda bruta de la cuenca Jequetepeque durante 2017-2018.

\begin{tabular}{|l|c|}
\hline \multicolumn{1}{|c|}{ Datos } & Resultados \\
\hline Número total & 12 \\
\hline Estadístico de contraste & 33.000 \\
\hline Error estándar & 12.748 \\
\hline Estadístico de contraste estandarizado & -0.471 \\
\hline Sig. asintótica (prueba bilateral) & 0.638 \\
\hline
\end{tabular}

Tabla 9. Test para normalidad multivariada en relación con la demanda agrícola de la cuenca Jequetepeque durante el año 20172018.

\begin{tabular}{|l|l|l|}
\hline $\begin{array}{l}\text { Henze-Zirkler }= \\
0.8085096\end{array}$ & Chi2(1) =4.563 & $\begin{array}{l}\text { Prob }>\text { chi2 }= \\
0.0327\end{array}$ \\
\hline Doornik-Hansen & Chi2(4) =8.554 & $\begin{array}{l}\text { Prob }>\text { chi2 }= \\
0.0733\end{array}$ \\
& & \\
\hline
\end{tabular}


2021, Instituto Mexicano de Tecnología del Agua Open Access bajo la licencia CC BY-NC-SA 4.0 sa/4.0/)

Tabla 10. Programa de Spearman, stats (rho p) pw en relación con la demanda agrícola de la cuenca Jequetepeque durante el año 20172018.

\begin{tabular}{|l|c|}
\hline \multicolumn{2}{|c|}{ Programa Spearman ejecutado, stats (rho p) pw } \\
\hline Número de objetos & 12 \\
\hline rho de Spearman & 0.8392 \\
\hline \multicolumn{2}{|c|}{ Test de Ho: programa para ejecutar si son variables independientes } \\
\hline Prob > $|\mathrm{t}|$ & 0.0006 \\
\hline
\end{tabular}

Tabla 11. Prueba de rangos con signo de Wilcoxon para muestras relacionadas según demanda agrícola de la cuenca Jequetepeque durante 2017-2018.

\begin{tabular}{|l|c|}
\hline \multicolumn{1}{|c|}{ Datos } & Resultados \\
\hline Número total & 12 \\
\hline Estadístico de contraste & 31.000 \\
\hline Error estándar & 12.748 \\
\hline Estadístico de contraste estandarizado & -0.628 \\
\hline Sig. asintótica (prueba bilateral) & 0.530 \\
\hline
\end{tabular}

La calidad del agua está afectada por diversos factores, como usos del suelo; producción industrial y agrícola; tratamiento que se le da antes de ser vertida nuevamente a los cuerpos de agua, y a la cantidad misma del agua de los ríos y lagos, ya que de ésta depende su capacidad de purificación. Calidad del agua es un término ampliamente usado, sin embargo, la cuantificación científica resulta 


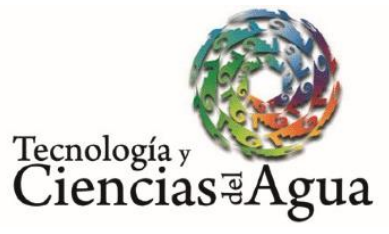

2021, Instituto Mexicano de Tecnología del Agua Open Access bajo la licencia CC BY-NC-SA 4.0 (https://creativecommons.org/licenses/by-ncsa/4.0/)

bastante importante y esta solución es una estrategia básica en el desarrollo de los fundamentos para el manejo de los recursos hídricos (Parparov, Hambrigh, Hakanson, \& Ostapenia, 2006). Existen muchos factores, físico-químicos y microbiológicos que permiten saber si determinados cuerpos de agua están contaminados o no. Esto significa que si hay alteración en los parámetros establecidos se presentan contaminación, aunque la sola presencia de una sustancia extraña en el agua no implica que exista alteración o contaminación del recurso hídrico, salvo que se produzca algún impacto sobre un ser vivo o material (Bonet \& Ricardo, 2011; Guerrero, 2014).

La calidad de agua de riego es muy importante para disminuir el problema de la concentración total de sales solubles presentes en el agua; a mayor cantidad de sales menor calidad de agua (Guerrero, 2016). Los factores que influyen sobre la calidad de agua en la zona son el $\mathrm{pH}$, la presencia de cationes [calcio $\left(\mathrm{Ca}^{+2}\right)$ y magnesio $\left(\mathrm{Mg}^{+2}\right)$ ] y la conductividad eléctrica (Palancar, 2006; Cortés-Jiménez, TroyoDiéguez, \& Murillo-Amador, 2009; Lingaswamy \& Saxena, 2015).

Los parámetros físico-químicos y microbiológicos, como: temperatura $(\mathrm{t})$; potencial de hidrógeno $(\mathrm{pH})$; conductividad eléctrica (CE); sólidos totales disueltos (SDT); oxígeno disuelto (OD); demanda bioquímica de oxígeno $\left(\mathrm{DBO}_{5}\right)$; calcio $\left(\mathrm{Ca}^{+2}\right)$; magnesio $\left(\mathrm{Mg}^{+2}\right)$; sodio $\left(\mathrm{Na}^{+1}\right)$; carbonatos $\left(\mathrm{CO}_{3}^{-2}\right)$; bicarbonatos $\left(\mathrm{HCO}_{3}^{-1}\right)$; cloruros $\left(\mathrm{Cl}^{-1}\right)$; metales, entre ellos, plomo $(\mathrm{Pb})$ y cadmio $(\mathrm{Cd})$; y coliformes totales y termotolerantes $(\mathrm{NMP} / 100 \mathrm{ml})$ en las diferentes estaciones de muestreo se presentan en la Figura 8, Figura 9 y Figura 10. Estos resultados se compararon con los estándares de calidad de aguas, según ECA D.S. N004-2017-MINAM y las Normas de Calidad Ambiental (NCA) de la Unión Europea (UE, 2013). 
2021, Instituto Mexicano de Tecnología del Agua

Tecnología y Open Access bajo la licencia CC BY-NC-SA 4.0 (https://creativecommons.org/licenses/by-nc$\mathrm{sa} / 4.0 /$ )
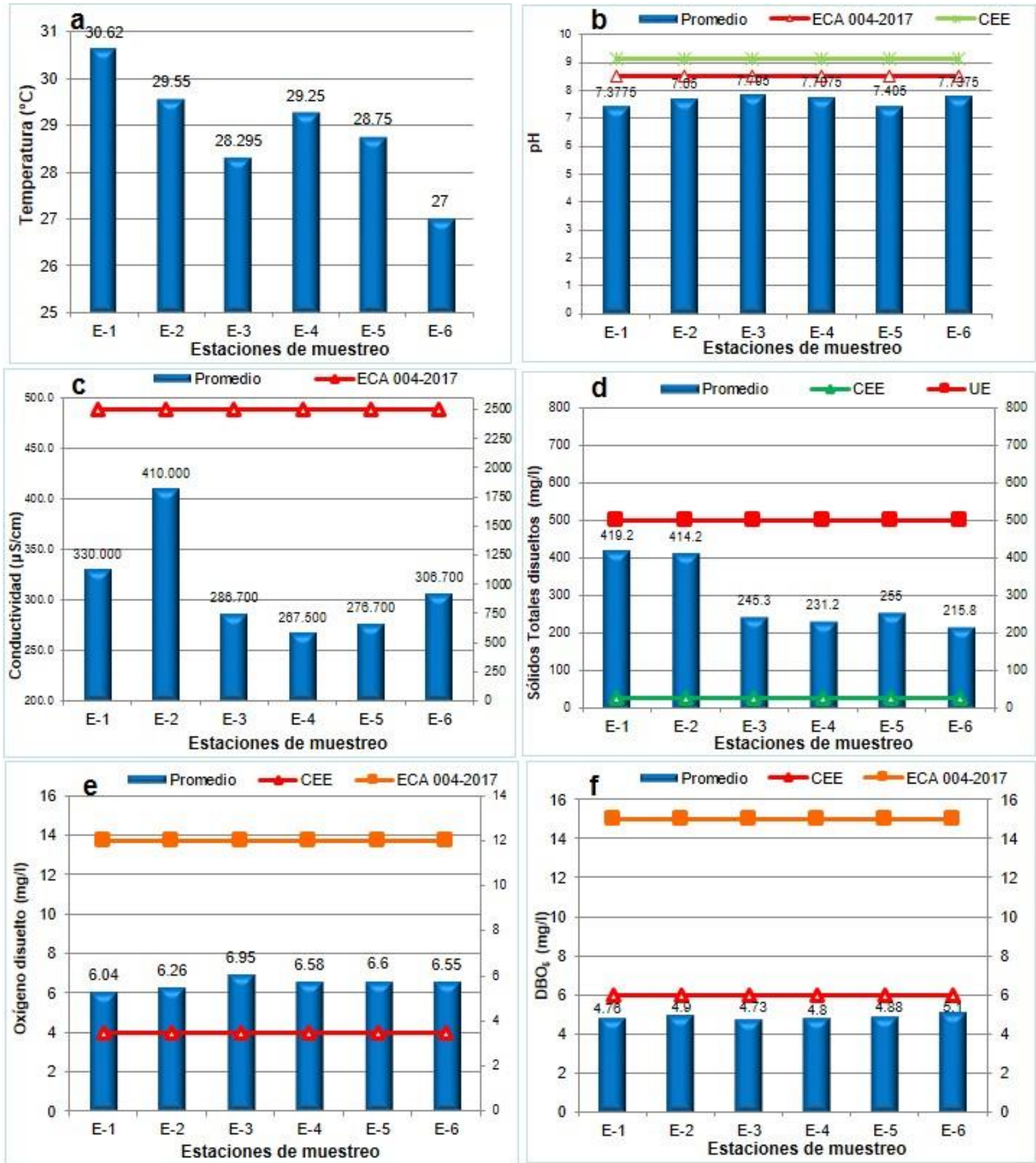

Figura 8. Evaluación de parámetros físico-químicos: a) temperatura;

b) $\mathrm{pH}$; c) conductividad; d) sólidos totales disueltos; e) oxígeno disuelto; f) demanda bioquímica de oxígeno en la cuenca media del 
2021, Instituto Mexicano de Tecnología del Agua Open Access bajo la licencia CC BY-NC-SA 4.0

Tecnología y (https://creativecommons.org/licenses/by-ncsa/4.0/)

río Jequetepeque, Perú. ECA = estándares de calidad ambiental del agua-Perú (D.S. N004-2017-MINAM). CEE = Comunidad Económica Europea (Directiva 2008/105/CE DEL Parlamento Europeo y del Consejo de 16 de diciembre de 2008. UE = Unión Europea (UE, 2013) (Directiva 2013/39/UE del Parlamento Europeo y del Consejo de 12 de agosto de 2013). 
2021, Instituto Mexicano de Tecnología del Agua Open Access bajo la licencia CC BY-NC-SA 4.0
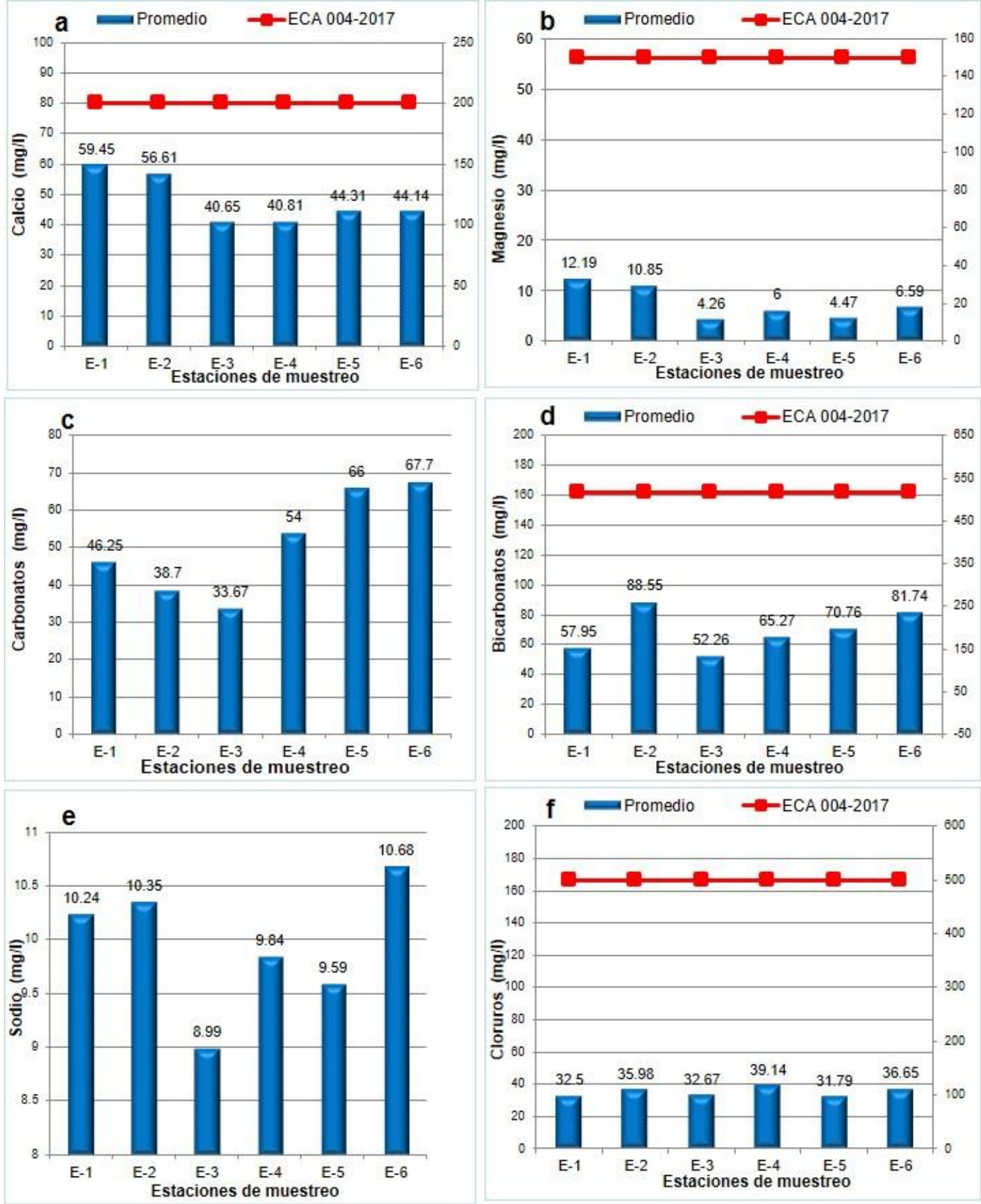

Figura 9. Evaluación de parámetros químicos: a) calcio; b) magnesio; c), carbonatos; d), bicarbonatos; e) sodio, y f) cloruros en la cuenca media del río Jequetepeque, Perú. ECA = estándares de calidad ambiental del agua-Perú (D.S. N004-2017-MINAM). 
2021, Instituto Mexicano de Tecnología del Agua

Tecnología y

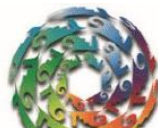

Open Access bajo la licencia CC BY-NC-SA 4.0

Ciencias $₫$ Agua

(https://creativecommons.org/licenses/by-ncsa/4.0/)
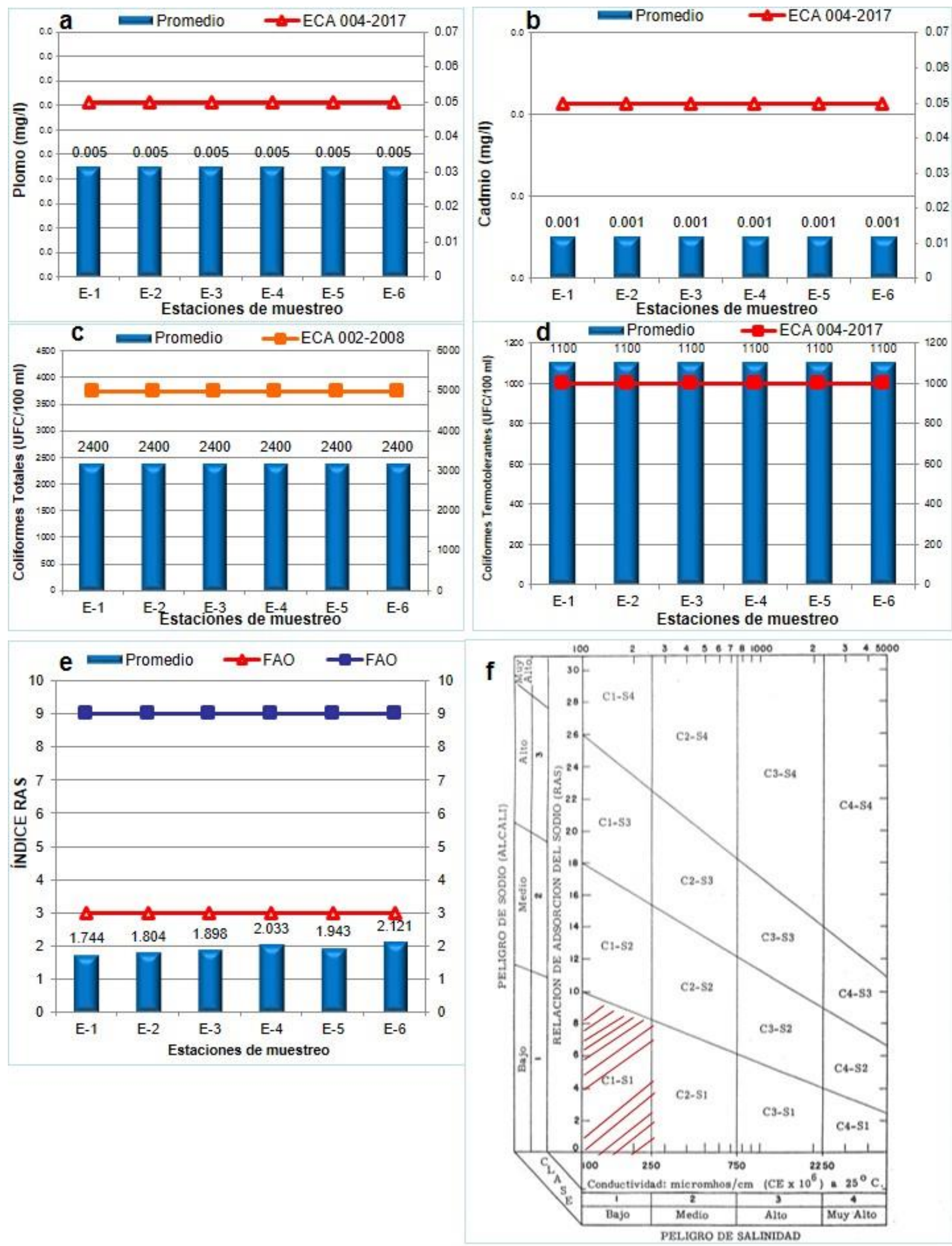
Figura 10. Evaluación de parámetros químicos y bacteriológicos: a) plomo; b) cadmio; c) coliformes totales; d) coliformes termotolerantes, y e) y f) determinación de índice y diagrama de RAS en la cuenca media del río Jequetepeque, Perú. ECA = estándares de calidad ambiental del agua-Perú (D.S. N002-2008-MINAM) (MINAM, 2008). ECA = estándares de calidad ambiental del agua-Perú (D.S. $N^{\circ}$ 004-2017-MINAM). FAO $=$ Food and Agriculture Organization of the United Nations (FAO). Soil erosion (FAO, 2019).

Todos los parámetros evaluados estaban dentro de los valores estándares de calidad de agua, excepto en los parámetros bacteriológicos coliformes totales y termotolerantes, que superaron las normas ECA D.S. N004-2017-MINAM, lo cual no es equivalente a las normas de la Unión Europea (UE, 2013); no existe equivalencia en ninguno de los casos.

Castañé, Topolián, Cordero y Salibián (2003), citados por Salas (2014), clasifican $\mathrm{Hg}, \mathrm{As}, \mathrm{Cr}, \mathrm{Pb}, \mathrm{Ni}$ y $\mathrm{Zn}$ como los metales de mayor efecto toxicológico y ecotoxicológico en ambientes acuáticos; en tanto Prieto, González, Román y Prieto (2009) consideran Hg, Cd, As, Cr, TI y $\mathrm{Pb}$. Sin embargo, es pertinente mencionar que el cobre $\left(\mathrm{Cu}^{1,2}\right)$ es un elemento esencial, requerido por las plantas y animales, y en altas concentraciones tiene efecto citotóxico (Gaete, Aránguiz, Cienfuegos, \& Tejos, 2007), mientras que los otros metales mencionados líneas arriba no tienen funciones metabólicas, como el cobre, por lo que no se biodegradan y bioacumulan en los tejidos, y podrían afectar el sistema nervioso central y/o llegar a ser cancerígenos. El valor promedio de plomo $(\mathrm{Pb})$ encontrado en todas las estaciones de monitoreo de la cuenca media del río Jequetepeque fue de $0.005 \mathrm{mg} / \mathrm{l}$ 


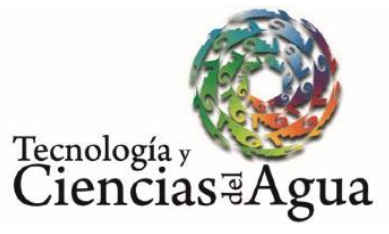

2021, Instituto Mexicano de Tecnología del Agua Open Access bajo la licencia CC BY-NC-SA 4.0 (https://creativecommons.org/licenses/by-ncsa/4.0/)

(Figura 10a). El plomo no se encuentra en los cuerpos de agua de forma natural, proviene de contaminación por arsenato de plomo y otras sales, especialmente de efluentes mineros. El plomo se bioacumula en huesos, puede producir daño al sistema nervioso central, y por consumo prolongado de aguas contaminadas con plomo tiene efectos letales.

El valor promedio de cadmio encontrado en todas las estaciones de monitoreo de la cuenca media del río Jequetepeque fue de 0.001 $\mathrm{mg} / \mathrm{l}$ (Figura 10b). El cadmio es elemento metálico soluble en agua, como los cloruros, nitratos y sulfatos, poco común en aguas naturales. Además de causar náuseas y vómitos, se bioacumula en el hígado, páncreas, tiroides y riñones; se considera elemento cancerígeno. Su presencia en aguas por lo general proviene de contaminación con residuos de la industria de galvanoplastia. Buenfil-Rojas y FloresCuevas (2007) afirman que la contaminación del río Hondo por metales pesados ( $\mathrm{As}, \mathrm{Cd}, \mathrm{Pb}$ y $\mathrm{Hg}$ ) provienen de los ingenios azucareros por el uso de plaguicidas y fertilizantes, así como por las descargas directas de aguas residuales en diferentes puntos de la ribera y por los residuos de la pequeña industria.

La determinación de coliformes totales (Figura 10c) no ha sido considerada en la normatividad peruana, Categoría 3: Riego de vegetales y bebida de animales y D1: Riego de vegetales (D.S. N0042017-MINAM) (MINAM, 2017), cuyo parámetro fue considerado en D.S. N002-2008-MINAM (MINAM, 2008); sin embargo, actualmente el mencionado decreto supremo fue derogado. Sin embargo, los coliformes termotolerantes (Figura 10d) en las seis estaciones de monitoreo superaron el valor estándar (1000 UFC/100 ml) según la 
Categoría 3: Riego de vegetales y bebida de animales y D1: Riego de vegetales (D.S. N004-2017-MINAM).

La temperatura, los sólidos totales disueltos, así como la materia orgánica, se encuentran en relación directa con la supervivencia y tasas de proliferación de los microorganismos, entre ellos los coliformes totales y fecales, estos últimos asociados con bacterias patógenas. Asimismo, es pertinente mencionar que en la zona de estudios se presentan pequeños centros poblados, cuyos vertimientos domésticos descargan directamente en la cuenca del río Jequetepeque; como consecuencia de ello se encontró que los coliformes termotolerantes (Figura 10d) superaron los estándares de calidad (ECA) para uso agrícola (D.S. N004-2017-MINAM). Sin embargo, estudios realizados por Lessard y Sieburth (1983), Rozen y Belkin (2001), y Cabral (2010) afirman que la temperatura no está relacionada con la supervivencia y proliferación de microorganismos, tal como lo demostraron Davies y Evison (1991), al no encontrar diferencias significativas en la tasa de supervivencia de Salmonella montevideo sometida a temperaturas de 5,15 y $25^{\circ} \mathrm{C}$.

El índice RAS se usa en la relación de absorción de sodio (CanChulim, Ramírez-Ayala, Ortega-Escobar, Trejo-López, \& Cruz-Díaz, 2008), que expresa la relación entre los iones de sodio, y la relación con los cationes de calcio y magnesio. En la Figura 10e se observa que el valor menor (1.744) se encontró en la estación Puente Kuntur Wasi (E-1), mientras que el mayor valor promedio (2.121) se encontró en la estación Puente Yonan (E-6). Los valores encontrados en todas las estaciones fueron menores a 3; según las normas de FAO (Ayers \& Westcot, 1987), no existe ninguna restricción del uso de agua para riego (Figura 10f). Asimismo, estudios realizados en calidad del agua 
de riego en la Sierra Norte de Puebla, México, encontraron valores promedio de 1.0 para la relación de absorción de sodio con relación entre iones de sodio y cationes de calcio y magnesio (RAS), y concluyeron que es óptimo para uso agrícola (Can-Chulim, OrtegaEscobar, Sánchez-Bernal, \& Cruz-Crespo, 2014).

Sin embargo, es importante resaltar que la agricultura aporta de manera constante diferentes tipos de contaminantes (sales procedentes del riego, pesticidas, fertilizantes, entre otros), por lo que la evaluación del aprovechamiento del agua en este sector requiere considerar otros aspectos, además de los puramente cuantitativos (Söderbaum \& Tortajada, 2011). Las aguas de retorno (aguas de escorrentía y percolación), por su elevada salinidad y contenido en nutrientes pueden producir un impacto medioambiental negativo sobre las masas de agua (superficiales o subterráneas) que las reciben, condicionando la calidad de las aguas de ríos y acuíferos tanto para el riego como para otros usos (Thayalakumaran, Bethune, \& Mcmahon, 2007).

\section{Conclusiones}

La calidad del agua de la cuenca media del río Jequetepeque se encontró dentro de la Categoría 3: Riego de vegetales y bebida de animales, y D1: Riego de vegetales; según los estándares de calidad 
ECA D.S. N004-2017-MINAM puede usarse sin restricciones para los diferentes cultivos de la zona de estudio. Mediante el coeficiente de correlación no paramétrica de Spearman se encontró $P<0.05$. Asimismo, con la prueba de distribución bivalente de Wilcoxon se encontró significancia asintótica de 0.638 y 0.53 .

El índice de absorción de sodio (RAS) encontró valores menores a 3, lo cual indica que no es limitante para la actividad agrícola; puede usarse sin restricciones para los diferentes cultivos de la zona de estudio.

La calidad del agua de la cuenca es alterada de forma moderada por las aportaciones o vertimientos de origen doméstico a lo largo de la cuenca. Sin embargo, es importante indicar que los valores promedios de coliformes termotolerantes superaron los estándares de calidad ambiental del D.S. N004-2017-MINAM (MINAM, 2017).

\section{Agradecimientos}

Especial agradecimiento por el apoyo brindado para el desarrollo de la presente investigación de dos importantes universidades del Perú: la Universidad Nacional de Trujillo y la Universidad Nacional Mayor de San Marcos.

\section{Referencias}

Álvarez, J., Panta, J., Ayala, C., \& Acosta, E. (2008). Calidad integral del agua superficial en la cuenca del río Amajac, Hidalgo, México. Información Tecnológica, 19(6), 21-32. 
Ciencias $₫$ Agua
2021, Instituto Mexicano de Tecnología del Agua Open Access bajo la licencia CC BY-NC-SA 4.0 (https://creativecommons.org/licenses/by-nc$\mathrm{sa} / 4.0 /)$

APHA-AWWA-WEF, American Public Health Association-American Water Works Association-World Economic Forum. (2012). Standard methods for examination of water and wastewater. (22nd ed.). Washington, DC, USA: American Public Health Association.

ANA, Autoridad Nacional del Agua. (11 de enero, 2016). Protocolo Nacional para el Monitoreo de la Calidad de los Recursos Hídricos. Resolución Jefatural N010-2016 ANA. El Peruano. Normas Legales, 575300-575301.

Ayers, R. S., \& Westcot, D. W. (1987). La calidad del agua y su uso en la agricultura. Riego y Drenaje, Food and Agriculture Organization of the United Nations, 29(1), 81.

Báez, A. (1999). Efecto de la calidad del agua de riego sobre las propiedades del suelo (monografía para optar el grado académico de especialista en Producción Vegetal). Universidad Nacional de Mar del Plata. Buenos Aires, Argentina. Recuperado de http://www.inta.gov.ar/barrow/info/documentos/agricultura/pdf/ TesisBaez.pdf

Balmaseda, C., \& García, Y. (2013). Calidad de las aguas de la Cuenca del río Naranjo, Municipio Majibacoa, provincial Las Tunas para el riego. Cultivos Tropicales, 34(4), 68-73.

Bermejillo, A., Martí, L., Cónsoli, D., Salcedo, C., Llera, J., Valdés, A., Vernier, M., \& Troilo, S. (2012). Aptitud para riego del agua subterránea basada en la salinidad y sodicidad en las perforaciones realizadas entre 2004 y 2014 en los Oasis Norte y Centro de Mendoza. Revista de la Facultad de Ciencias Agrarias UNCuyo, 44(2), 221-240. 
Bonet, C., \& Ricardo, M. (2011). Calidad de riego y su posible efecto en los rendimientos agrícolas en la empresa de cultivos varios sierra de Cubitas. Revista Ciencias Técnicas Agropecuarias, 20(3), 19-23.

Buenfil-Rojas, M., \& Flores-Cuevas, N. (2007). Determinación de metales pesados ( $\mathrm{As}, \mathrm{Cd}, \mathrm{Hg}$ y $\mathrm{Pb}$ ) presentes en el río Hondo, Quintana Roo. Memorias en extenso (pp. 435-439). VI Congreso Internacional y XII Nacional de Ciencias Ambientales, Chihuahua, México.

Cabral, J. (2010). Water microbiology. Bacterial pathogens and water. International Journal of Environmental Research and Public Health, 7(10), 3657-3703.

Can-Chulim, A., Ortega-Escobar, H. M., Sánchez-Bernal, E. I., \& CruzCrespo, E. (2014). Calidad del agua para riego en la Sierra Norte de Puebla, México. Tecnología y ciencias del agua, 5(5), 77-96.

Can-Chulim, Á., Ramírez-Ayala, C., Ortega-Escobar, M., Trejo-López, C., \& Cruz-Díaz, J. (2008). Evaluación de la relación de adsorción de sodio en las aguas del río Tulancingo, estado de Hidalgo, México. Terra Latinoamericana, 26(3), 243-252.

Castañé, M., Topolián, L., Cordero, R., \& Salibián, A. (2003). Influencia de la especiación de los metales pesados en el medio acuático como determinante de su toxicidad. Revista de Toxicología, 20, 13-18.

Cortés-Jiménez, J. M., Troyo-Diéguez, E. \& Murillo-Amador, E. (2009). Índices de calidad del agua del acuífero del valle del Yaqui Sonora. Terra Latinoamericana, 27(2), 133-141. 
2021, Instituto Mexicano de Tecnología del Agua Open Access bajo la licencia CC BY-NC-SA 4.0 (https://creativecommons.org/licenses/by-nc$\mathrm{sa} / 4.0 /)$

Davies, C., \& Evison, L. (1991). Sunlight and the survival of enteric bacteria in natural waters. Journal of Applied Microbiology, 3(70), 265-274.

FAO, Food and Agriculture Organization of the United Nations. (2019). Soil erosion: The greatest challenge to sustainable soil management. Rome, Italy: Food and Agriculture Organization of the United Nations.

FAO, Food and Agriculture Organization of the United Nations. (2002). Agricultural drainage water management in arid and semiarid areas (Paper No 61). Rome, Italy: FAO Irrigation and Drainage.

Gaete, H., Aránguiz, F., Cienfuegos, G., \& Tejos, M. (2007). Metales pesados y toxicidad de aguas del río Aconcagua en Chile. Química Nova, 30(4), 885-891.

GEMS, Global Environmental Monitoring System. (1987). GEMS/Water Operational Guide. Geneva, Italy: Prepared under the joint sponsorship of the United Nations Environmental Programme. World Health Organization, United Nations Educational, Scientific and Cultural Organization, World Meteorological Organization, World Health Organization.

Guerrero, A. M. (2016). Análisis de calidad de agua de la cuenca hidrográfica Chicama, Perú. Gestión Ambiental, 31, 51-62.

Guerrero, A. M. (2014). Gestión integrada de recursos hídricos de la cuenca del río Jequetepeque, Perú. Sciendo, 17(2), 92-116.

Gyawali, S., Techato, K., Yuangyai, C., \& Musikavong, C. (2013). Assessment of relationship between land uses of riparian zone and water quality of river for sustainable development of river basin, 
a case study of U-Tapao River Basin, Thailand. Procedia Environmental Sciences, 17, 291-297.

Hakanson, L., Parparov, A., Ostapenia, A., Boulion, V., \& Hambrig, K. D. (2000). Development of a system of water quality as a tool for management. Final report to INTAS. Upsala, Sweden: Uppsala University, Department of Earth Science.

Hernández, R., Fernández, C., \& Baptista, M. (2010). Metodología de la investigación ( $5^{a}$ ed.). México, DF, México: McGrawHill/Interamericana Editores, S.A. de C.V.

Hines, W., \& Montgomery, D. (1996). Probabilidad y estadística para ingeniería y administración ( $3^{a}$ ed.). México, DF, México: Compañía Editorial Continental, S.A. de C.V.

INRENA, Instituto Nacional de Evaluación de Recursos Naturales. (2003). Evaluación y ordenamiento de los recursos hídricos en la cuenca del río Chicama. Hidrología. Estudio Hidrológico. Lima, Perú: Ministerio de Agricultura, Instituto Nacional de Evaluación de Recursos Naturales.

Juarez, H. (2006). Contaminación del río Rímac por metales pesados y efecto en la agricultura en el cono este de Lima metropolitana. Lima, Perú: Universidad Agraria La Molina.

Lessard, E. J., \& Sieburth, J. (1983). Survival of natural sewage populations of enteric bacteria in diffusion and batch chambers in the marine environment. Applied and Environmental Microbiology, 45(3), 950-959.

Lingaswamy, M., \& Saxena, P. R. (2015). Water quality of Fox Sagar Lake, Hyderabad, Telangana State, India, its suitability for 
Ciencias $₫$ Agua
2021, Instituto Mexicano de Tecnología del Agua Open Access bajo la licencia CC BY-NC-SA 4.0 (https://creativecommons.org/licenses/by-nc$\mathrm{sa} / 4.0 /$ )

irrigation purpose. International Journal of Advanced Research in Science, Engineering and Technology, 4(8), 490-494.

Medeiros, A., Freitas, K. R., Freitas, K., Do, C., Da-Silva, I., DeOliveira, M., Guimarãesb, R., \& Mendonçac, N. (2017). Quality index of the surface water of Amazonian rivers in industrial areas in Pará, Brazil. Marine Pollution Bulletin, 123(1-2), 156-164.

MINAM, Ministerio del Ambiente. (7 de junio, 2017). Aprueban Estándares de Calidad Ambiental (ECA) para Agua y establecen Disposiciones Complementarias. Decreto Supremo N004-2017MINAM. Diario "El Peruano", 10-19.

MINAM, Ministerio del Ambiente. (30 de julio, 2008). Aprueban los Estándares Nacionales de Calidad Ambiental (ECA) para el Agua y Disposiciones Complementarias Transitorias. Decreto Supremo Nº02-2008-MINAM. Diario "El Peruano", Perú, 12 pp.

Ocampo-Duque, W., Osorio, C., Piamba, C., Schuhmacker, M., \& Domingo, J. (2013). Water quality analysis in rivers with nonparametric probability distributions and fuzzy inference systems: application to the Cauca River, Colombia. Environment International, 52, 17-28.

Pawar, P. R. (2013). Monitoring of impact of anthropogenic inputs on water quality of mangrove ecosystem of Uran, Navi Mumbai, west coast of India. Marine Pollution Bulletin, 75(1-2), 291-300.

Palancar, T. (2006). Compresibilidad y resistencia al corte de suelos salinizados y sodificados por irrigación (tesis doctoral). Universidad Nacional de la Plata, La Plata-Argentina. Recuperado de https://doi.org/10.4995/Thesis/10251/1939 


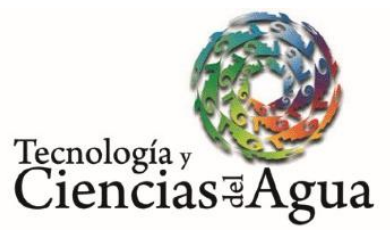

2021, Instituto Mexicano de Tecnología del Agua Open Access bajo la licencia CC BY-NC-SA 4.0 (https://creativecommons.org/licenses/by-nc$\mathrm{sa} / 4.0 /$ )

Peña, H. (1993). Caracterización de la calidad de las aguas naturales y contaminación agrícola en Chile. En: Prevención de la contaminación del agua por la agricultura y actividades afines. Anales de la Consulta de Expertos Organizada por la FAO. Santiago, Chile: Editorial de la Organización de las Naciones Unidas para la Alimentación y la Agricultura.

Pérez, J., Nardini, A., \& Galindo, A. (2018). Análisis comparativo de índices de calidad del agua aplicados al río Ranchería, La GuajiraColombia. Información Tecnológica, 29(3), 47-58.

Posada, J., Roldán, G., \& Ramírez, J. (2000). Caracterización fisicoquímica y biológica de la calidad de aguas de la cuenca de la quebrada Piedra Blancas, Antioquia. Colombia. Revista Bioltrop $V$, 48(1), 0034-7744.

Prieto, J., González, C., Román, A., \& Prieto, F. (2009). Contaminación y fitotoxicidad en plantas por metales pesados provenientes de suelos y agua. Tropical and Subtropical Agroecosystems, 10, 2944.

Rangeti, I., Dzwairo, B., Barratt, G., \& Otieno, F. (2015). Ecosystemspecific water quality indices. African Journal of Aquatic Science, 40(3), 227-234.

Rashidi, M., \& Seilsepour, M. (2011). Prediction of soil sodium adsorption ratio base on soil electrical conductivity. Middle-East Journal of Scientific Research, 8(2), 379-383.

Reinaudi, N. , Grégoire, H., Rosiére, J., Nadal, D., \& Viñuela, R. (1998). Calidad del agua para riego en invernáculos de la Región Central de la Pampa. Santa Rosa La Pampa, Argentina: Facultad de 
Agronomía.

Recuperado

de

http://libnet.unse.edu.ar/5Con/Rhid/T/03021.PDF

Rivera, N., Encina, F., Palma, R., \& Mejias, P. (2009). La calidad de las aguas en el curso superior y medio del río Traiguén, IX RegiónChile. Información Tecnológica, 20(4), 75-84.

Roldan, J., Díaz, M., Pérez, R., \& Moreno, M. (2010). Mejora de la gestión del agua de riego mediante el uso de indicadores de riego. Revista de la Facultad de Ciencias Agrarias, Universidad Nacional de Cuyo. Mendoza, Argentina, 42(1), 104-124.

Romero, J. (2019). Calidad del agua. Edición 3R/2019. Bogotá, Colombia: Escuela Colombiana de Ingeniería.

Rozen, Y., \& Belkin, S. (2001). Survival of enteric bacteria in seawater. FEMS Microbiology Reviews, 25(1), 513-529.

Salas, F. (2014). Determinación de metales pesados en las aguas del río Ananea debido a la actividad minera aurífera, Puno-Perú. Revista de Investigaciones, 5(4), 47-53.

Sarabia-Meléndez, I. F., Cisneros-Almazán, R., Aceves-De-Alba, J., Durán-García, H. M., \& Castro-Larragoitia, J. (2011). Calidad de agua de riego en suelos agrícolas y cultivos del valle de San Luis Potosí, México. Revista Internacional de Contaminación Ambiental, 27(2), 103-113.

Söderbaum, P., \& Tortajada, C. (2011). Perspectives for water management within the context of sustainable development. Water International, 36(7), 812-827.

Solís, G., Israel, A., Nubes, G., Castillo, J., \& Meraz, F. (2011). Fisicoquímica del agua superficial y sedimento en el río Santa Cruz, Sonora. México. Revista Biotecnia, 13(1), 3-9. 
Sutadian, A. D., Muttil, N., Yilmaz, A. G., \& Perera, B. J. C. (2016). Development of river water quality indices-a review. Environmental Monitoring and Assessment, 188, 58.

Thayalakumaran, T., Bethune, M. G., \& Mcmahon, T. A. (2007). Achieving a salt balance- Should it be a management objective? Agricultural Water Management, 92, 1-12.

Tyagi, S., Sharma, P., Singh, P., \& Dobhal, R. (2013). Water quality assessment in terms of water quality index. American Journal of Water Resources, 1(3), 34-38.

UE, Unión Europea. (2013). Normas de calidad ambiental aplicables a las aguas superficiales (UE). Directiva 2013/39/UE del Parlamento Europeo y del Consejo de 12 de agosto de 2013. Recuperado de http://eur-

lex.europa.eu/LexUriServ/LexUriServ.do?uri=0]:I:2013:226:000 $1: 001$ 